\title{
Urban Public Bicycle Rental Point Location Method Research
}

\author{
Chaoqun Ma, Quantao YANG, Kepeng YANG, YuanLi \\ C.Q. Ma, Q.T .YANG, K.P. YANG, YuanLi \\ School of Highway, Chang 'an university, Xi 'an,China
}

\begin{abstract}
KEYWORD: Public bike; Rental point;Gravity method
ABSTRACT: In order to solve such problems as environmental pollution, motor vehicle growth cities in our country has made a priority to the development of green public bicycle transportation strategy; First elaborates on the development of public bicycle industry in our country, and combining the land use status of public bicycle transportation in our country is analyzed, by using gravity method to choose public bike rental point, so as to choose the best walking distance in public bike rental service scope biggest points, to guide the development of public bicycle transportation has important practical significance..
\end{abstract}

\section{INTRODUCTION}

Bike-sharing in cities is a low-carbon and an environment-friendly kind of transportation.Bikesharing system is composed of the lease point and bicycle road network. In order to better understand the relationship between the lease point and the road, the scholars establish complex network theory [1] to analyze, and use inventory model [2] to certify the connection between the lease point position and the number of bicycles to provide a dynamic data transmission system based on android [3] to the traveler to inform the travelers a dynamic situation of the lease point. In this system, the selection of lease point is the most crucial step, in doing so, it will determine the capacity to attract the people [4]. As residents travel in multi-ways and environmental pollution deepens, cities in China, in line with the call of the government, have set up a public bicycle transportation system to alleviate the negative effects of urban transportation. That is to say, give the priority to the development of public bicycle, which is the most simple way to solve traffic jam and pollution of the environment problem.Bicycle is also the first choice for travel last mile[5.6] transportation.At present most of the city mainly consider the vicinity intensity around the lease point when setting up public bike rental point site, and easilylead to the coverage overlap;On the other hand because of the distance between setting, they cannot make the placing signage at lease point and demand at meet.So we need to find a reasonable rental point setting method, both to ensure have enough customers, and to guarantee the lease some coverage of duplication and overlap of [7.8].The center of gravity method is adopted to set up the lease point,considering the traffic situation and the future land usage around the lease point.

\section{THE PUBLIC BICYCLE CHARACTERISTICS}

In order to rationally set up the lease point,selecting test should take a few features [9.10]of the bikes in to consideration:

1. Short distance travel.Public bicycle, as a traditional and modern travel way, has the advantages of agility, flexibility. However, riding bicycle takes a certain amount of strength and energyand cycling speed is slow, so the bike only applies to short distance travel.In xi 'an investigation on riders concludes that bicycle travel distance-time chart, and find the best bicycle trip distance is within the 6.5 $\mathrm{km}$, best riding time within 25 min time. 


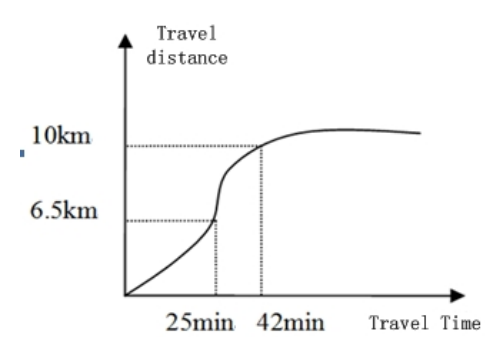

Figure 1 bike travel - time distance map

2. It is green travel and environmental friendly. Look from the bike itself characteristics: its structure is simple-two rounds of operation and take up less road area in working. The width of a twoway bike lanes is about $3 \mathrm{~m}$, takes roughly in the process of parking area $2.5 \mathrm{~m} 2$.From the perspective of the capacity mechanism of bicycle, bicycle drives by personalenergy, not only reduce the energy consumption, but also make the rider exercise in the short distance to travel to keep fit.

3.It is flexible and convenient. Bicycle flexible features determines it is easy to work because in the process of short distance travel, residents' main consideration is thed convenience and promptness of bicycle to realize door-to-door travel and bicycle, as other shuttle transportation tool, usually is set on the bicycle parking site at the bus station, such as rail stations, taxi stands and crisscross site with highly dentisity to transfer for the other transportation ways, which not only reduces the traveler demand for motor vehicles but alsomakes the best use of the bicycle.

\section{RENTAL POINT MODEL IS ESTABLISHED IN THIS PAPER}

Most cities in China are considered in setting the public bike rental passenger demand, to a certain extent, promote the development of China's public bicycle industry. Through the analysis of the characteristics of bicycle found that public bike rental point selection is very necessary, how to let the public bicycle exert larger connection and operation efficiency, need to optimize the selection of public bike rental point design. In this paper, center of gravity method is used to optimize the public bike rental point selection, lease point according to the layout of the ring plus radiation type planning [11.12].By analyzing hierarchy layout, on the one hand, to ensure the cohesion between different functional areas, on the other hand to avoid due to lease point layout unreasonable phenomenon such as bike missing or parking difficulties. In order to guarantee the rationality of the bicycle rental points, the following model:

$$
\left\{\begin{array}{l}
x=x_{0} v^{0}+x_{1} v^{1}+x_{2} v^{2}+\mathrm{L} \mathrm{L}+x_{N} v^{n} \\
x_{0} \geq 0, x_{1} \geq 0, x_{2} \geq 0, \mathrm{~L} \mathrm{~L} x_{n} \geq 0
\end{array}\right.
$$

Where: $v^{0}, v^{1}, v^{2} \mathbf{L} \mathbf{L} v^{n}$ are weight coefficients, and travelers to choose the lease point, $x_{0}, x_{1}$, $x_{2} \mathbf{L} \mathbf{L} x_{N}$ are leasing point coordinates. When $N=1$, on behalf of the traveler to choose between two points of lease. When $N=2$, a traveler in the plane to choose between three points of lease. Travelers to choose the optimal lease dot, need to choose different points of lease. Lease point $P$ hybrid strategy is to have several lease point of probability vector set. Traveler calculations take their mixed strategy $P=\left(p_{1}, p_{2}, p_{3}, p_{4} \mathrm{~L} \mathrm{~L} p_{n}\right)$ of optimal income or at least travel expenses $U$

$$
\left\{\begin{array}{l}
U=x_{0} p_{0}+x_{1} p_{1}+x_{2} p_{2}+\mathrm{L} \mathrm{L}+x_{n} p_{n} \\
p_{0}+p_{1}+p_{2}+\mathrm{L} \mathrm{L}+p_{n}=1 \\
0 \leq p_{i} \leq 1
\end{array}\right.
$$

From the perspective of the layout of the ring plus radiation type, mainly some a few features: (1)for rental bicycle parking, can realize exchange between multiple lease; (2) to meet the demand of different travel direction; (3) lease point after the layout is reasonable, to a certain extent the public bicycle can replace private vehicles, reduce late Gao Fengchong to traffic in the city. 


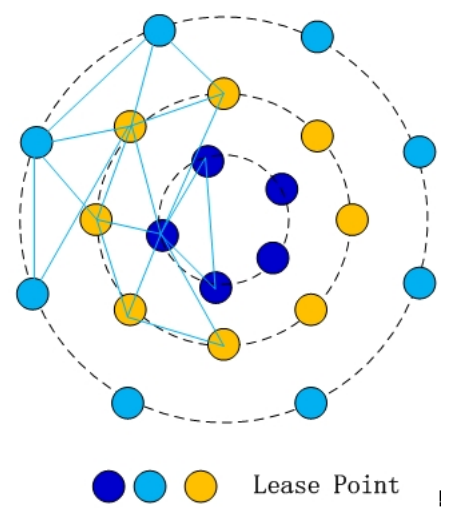

Figure 2 lease point setting map

On a single lease point layout using the center of gravity method for location selection, site in order to ensure that attract more travel, first divides the traffic area will present situation according to the actual situation of different land use types are divided into different neighborhood, don't break when village community based on the original line, to ensure the integrity of the community. Secondly, as far as possible the same types of land use as a class, easy to determine the plot to attract traffic. Finally, to ensure that the district division is moderate. To consider when dividing village residents acceptable optimum walk trip distance and place of the best bike rental service radius, general development control within $0.5 \mathrm{~km} 2$.

Defined area, coordinates to calibrate the village, because the village basic on the same horizontal plane, so only consider village of two-dimensional plane coordinates $(x, y)$.Determine the good village after the coordinates of the point, to calculate the barycentric coordinates of points. Considering the weight coefficient of different community, when solving village barycentric coordinates points should consider the weight coefficient of each village, ask barycentric coordinates is the theory of public bike rental point position. Calculation process is as follows:

$$
\left\{\begin{array}{l}
x_{0}=m_{1} x_{1}+m_{2} x_{2}+m_{3} x_{3}+\mathrm{L} \mathrm{L}+m_{n} x_{n} \\
y_{0}=m_{1} y_{1}+m_{2} y_{2}+m_{3} y_{3}+\mathrm{L} \mathrm{L}+m_{n} y_{n} \\
1=\sum_{i=1}^{n} m_{i}
\end{array}\right.
$$

In reality, due to the shortage of urban land, the desires of the theory of rental locations may be in the city's special position such as on the city roads, residential area, etc, so need to modify the theoretical position, mainly considering the surrounding land use characteristics in the process of correction, residents' travel behavior characteristics, traffic facilities nearby the village and hierarchy of surrounding roads, with the theoretical value as the origin of coordinates, with the $x$ axis direction, $y$ axis represents the north-south direction. According to the above factors determine the direction of east, west, south and north four impact value of $e_{1}, e_{2}, n_{1}, n_{2}$, Choose what direction the biggest impact value $^{a}$, the influence of north and south direction of the maximum value of $b$. According to the influence big shift in the direction of the theoretical values, until the theoretical position to reasonable use of land within the scope of and then calculate the actual lease point location $(\bar{x}, \bar{y})$.

$$
\begin{gathered}
\left\{\begin{array}{c}
a=\operatorname{Max}\left\{n_{1}, n_{2}\right\} \\
b=\operatorname{Max}\left\{e_{1}, e_{2}\right\}
\end{array}\right. \\
\left\{\begin{array}{l}
\bar{x}=x \pm a \\
\bar{y}=y \pm b
\end{array}\right.
\end{gathered}
$$




\section{THE MODEL PARAMETER CALIBRATION}

\section{Weight Factors}

Calibration weights $m$ main consideration to the importance of the district of public bike rental

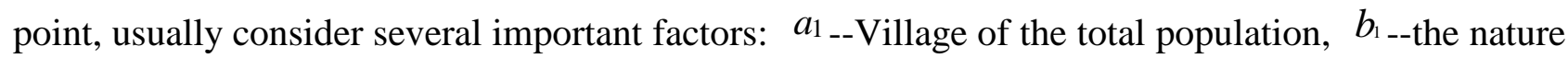
of the village land, $c_{1}$--area surrounding road network accessibility $\mathrm{C}$. Identify the influence factors of residential area, using the analytic hierarchy process to determine the relative importance between the evaluation factors order, finally get the relative weight of each community values.

\section{Village Population}

To measure the size of a cell can use residential area or population living in the community, in the division of community, often will residential area designated for the approximation of the same, so the population of the village to measure the influence degree of the area of public bike rental point.Population's influence on the public bicycle rental points mainly considering when population of the village, village travel demand is big, the demand for public bicycle will increase to a certain extent.

$$
a_{1}=\left(\sum_{i=1}^{n} C \times H\right) \times \eta \times m
$$

Wher, $n$ is the various floors of the building inside the village, $C$ is several floors, $\mathrm{H}$ is each layer number, $\eta$ is occupancy rate, $M$ is live average number per family.

\section{VillageLand Property}

Plot of land property to a certain extent, affected the village traveling attract amount, community to attract large amount of village public bike rental point effects, small conversely;Plot of land property consists of land for residential land, public facilities, land for commercial services, etc.Different measure land used by GIS software.

\section{Clear On The Surrounding Road Network}

Reflects the clear on the neighborhood surrounding roads area, the improvement of the traffic facilities nearby the clear on the surrounding roads well shows that the community and the surrounding area have more people exchange capacity, therefore, the village of bike rental point of attraction will increase.

$$
K_{i}=\left(\sum Z_{i j}+C_{i j}+L_{i j}\right) /(N-1)
$$

Where, $K_{i}$ is $i$ through the arterial road traffic plot, dry, and the branch to other district of the evaluation of distance, $Z_{i j}$ is traffic village $i$ to $j$ the village of the shortest distance distance, $C_{i j}$ is traffic village $i$ to $j$ village to city one of the shortest distance, $L_{i j}$ is traffic village $i$ to $j$ the village branch of the shortest distance.

\section{Coordinates Calibration}

Because of urban expressway and city distance as the backbone of the city plays an important role in supporting, and the ability to influence road surrounding land properties, thus coordinate system as far as possible choose the intersection of urban expressway and expressway, distance and arterial road or expressway and the arterial road, the road intersection point as the origin, intersecting roads as $X$ and $Y$ axes, respectively, so convenient computing community center coordinate system. For the intersection of nonorthogonal orthogonalization processing, convenient coordinate point calibration. Coordinates calibration when first using the GIS software to the calibration area measurement, and then find out the measure to centroid and calibration.

\section{CASE STUDY}

Take public bike rental at the south gate of Chang'an University headquarters for example to illustrate. Chang'an university headquarters is adjacent to the south road in the west, south 2nd ring in 
the south and faces Cui-Hua road. In order to better clarify the bike rental position,Chang'an University headquarters and the surrounding area are mapped in the two-dimensional plane coordinate system, on which the horizontal axis stands for the east street of Xingshan Temple, vertical axis for chang'an road, the intersection as a dot coordinates. And the vicinity is divided into four areas are: the south road residential district $A$, Chang 'an University teaching area $B$, Chang'an University residential area $C$ and Liberal Arts College in Xi' an residential area $D$, and mark the centroid point coordinates of each area.

Table 1. The parameter calibration

\begin{tabular}{ccccc}
\hline & A & B & C & D \\
\hline population & 3896 & 16230 & 4359 & 2563 \\
\hline The land area $\left(\mathrm{m}^{2}\right)$ & 166493 & 299520 & 108023 & 132569 \\
\hline Clear on the network $(\mathrm{m})$ & 473 & 425 & 527 & 493 \\
\hline Plot weight & 0.26 & 0.31 & 0.20 & 0.23 \\
\hline
\end{tabular}

By four small area, land use status and the number of travel research and clear on the surrounding road network based on analytic hierarchy process (ahp) to determine weight value of four vil-

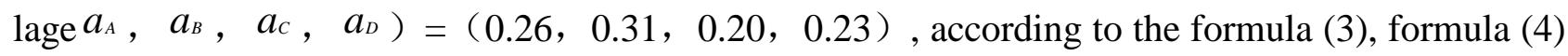
and formula (5) identify the coordinates of the point of public bike rental, (839, 69).Research carried out by the surrounding land with a point found surrounding land for building lease point coordinates.

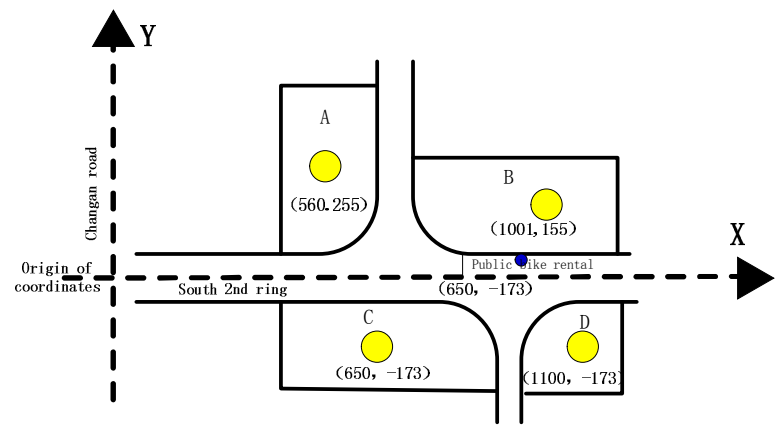

Figure 3 public bicycle planning site

\section{CONCLUSION}

This paper uses gravity method for public bike rental point selection, not only consider the traveler demand for public bicycle, but also take into account the lease land surrounding the point type comprehensive consideration, one hand, reduce the time traveler on foot; on the other hand can reflect public short distance transportation obvious advantages of bicycles, to guide the development of China's public bicycle transportation has a certain significance.

\section{ACKNOWLEDGMENT}

The project was supported by Natural Science Basic Research Plan in Shaanxi Province of China (Program No. 2016JM5063), and Science and Technology Research Plan of Ministry of Housing and Urban-Rural Development of China (Program No. 2016-K2-033).

\section{REFERENCES}

[1]Li Congying, Wang Zhaofei. Structure charcatertics of urban public bicycle layout network based on complex network. 2011 International Conference on Remote Sensing, Environment and Transportation Engineering, RSETE 2011 - Proceedings, p 5343-5345. 
[2]Lin JennRong, Yang TaHui, Chang YuChung. A hub location inventory model for bicycle sharing system design: Formulation and solution. Computers and Industrial Engineering, v 65, n 1, p 77-86, 2013.

[3]Liao Guihua, Zhangjian. Information query for public bicycle service based on Andriod. Proceedings 2014 IEEE International Conference on Security, Pattern Analysis, and Cybernetics, SPAC 2014, p 126-129, December 11, 2014.

[4]Zheng Chao, Wang Xifu,Wu Chun. Research on public bicycle rental station layout. Advanced Materials Research, Resources and Sustainable Development,v 734-737, p 1590-1593, 2013.

[5]Halgota V. Social Aspects of City Traffic Planning: Public Bicycles as a Part of Zagreb's Traffic Identity[J]. Diskrepancija, 2010, 10(14/15):60-71.

[6]Jennings G. Finding our balance: Considering the opportunities for public bicycle systems in Cape Town, South Africa[J]. Research in Transportation Business \& Management, 2014, 15:6-14.

[7]Qiu-ping Wang, Luo Ni. Bicycles and public transport parking facility location selection [J]. Journal of transportation science and technology and economy, 2013, 15 (6) : 14-17.

[8]Lihui Li, Hua Chen, Xiao-li Sun. Public bike rental point layout planning in Wuhan city [J]. Journal of urban traffic, 2009, 7 (4) : 39-44.

[9]Cheng-ming Zhu, Guang-ming Hu , Ya-dong Liu. Highway passenger transport hub siting urban planning [J]. Journal of chongqing jiaotong university: natural science edition, 2006, 25 (3) : 95-98.

[10]LiangGe, WeiWang, WeiDeng, etc. Urban passenger transfer hub planning and design method research [J]. Journal of planner, 2004, 20 (10) : 53-55.

[11]Geng Xue, Zhang Yu, etc. Paris public bike rental point planning and design [J]. Journal of urban traffic, 2009, 7 (4) : 21-29.

[12]Chen Hui, Miao Jing. Fuzhou public bike rental point location research [J]. Journal of institute of Minjiang, 2014, 35 (2) : 128-134. 